\title{
Estudio de la transmisión de la infección del VIH en el laboratorio de educación secundaria
}

\author{
Raquel Boronat Gil ${ }^{1}$, José Pedro López Pérez ${ }^{2}$ \\ ${ }^{1}$ IES Antonio Menárguez.Costa, 30710 Los Alcázares. Murcia.España.raquel.boronat@murciaeduca.es \\ ${ }^{2}$ IES Ricardo Ortega, 30320 Fuente Álamo. Murcia y Departamento de Didáctica de las Ciencias \\ Experimentales. Facultad de Educación. Universidad de Murcia. Campus de Espinardo. 30100 Murcia. \\ josepedro.lopez@murciaeduca.es
}

[Recibido en marzo de 2013, aceptado en octubre de 2013]

\begin{abstract}
El estudio de las enfermedades de transmisión sexual queda integrado en el currículo de Educación Secundaria Obligatoria y Bachillerato. En esta actividad práctica se presenta una sencilla experiencia para demostrar la cadena de transmisión del VIH, desde una perspectiva básica, mediante la ayuda de la ciencia recreativa.

Palabras clave: VIH; SIDA; Fenolftaleína; Ciencia recreativa; Educación Secundaria.
\end{abstract}

\section{Study of the transmission of HIV infection in the secondary education laboratory}

The study of sexually transmitted diseases is integrated in the Compulsory Secondary Education Curriculum. In this experience we present a simple experiment to show the HIV transmission chain, from a basic perspective, through the help of recreational science.

Keywords: HIV; AIDS; Phenolphthalein; Recreational Science; Secondary Education.

\section{Introducción y justificación del trabajo}

El estudio de las enfermedades de transmisión sexual en la Educación Secundaria Obligatoria (3ํ ESO, Biología y Geología. Bloque 5. Las personas y la Salud) (BOE 2006) y Bachillerato $\left(1^{\circ}\right.$ Bachillerato, Ciencias para el Mundo Contemporáneo. Bloque 3. Vivir más, vivir mejor; $2^{\circ}$ Bachillerato, Biología. Bloque 5. La Inmunología y sus Aplicaciones) (BOE 2007) lleva consigo la aproximación a la enfermedad conocida como síndrome de inmunodeficiencia adquirida (SIDA). Esta patología está causada por el virus de inmunodeficiencia humana (VIH), perteneciente a la familia de los retrovirus, con capacidad de atacar al complejo celular implicado en la defensa del organismo (Granados y López 2003).

A través de los estudios llevados a cabo durante los últimos años, las estadísticas reflejan una mortalidad altísima causada por este virus en nuestra sociedad, sobre todo en países y escalas sociales con bajo poder económico, con escasos sistemas para acceder a una sanidad de calidad. En un resumen elaborado por la Organización Mundial de la Salud para el año 2011 (OMS 2012), el número total de personas que conviven con el VIH en el mundo es de 34 millones, un 7,4\% más que en 2010. En este mismo informe se destaca la cifra de 1,7 millones, como las muertes causadas por este virus, de los que 230.000 comprenden a niños menores de 15 años. El informe también ofrece datos referidos a Europa Centro y Occidente, en cuando al número de personas que conviven con la infección (900.000), número de adultos y niños que han contraído el virus (30.000) y casos de muerte causada por SIDA en adultos y niños (7.000).

Si bien los datos sobre la evolución de la enfermedad del SIDA no son tranquilizadores para la sociedad, la medicina ha realizado un gran esfuerzo para encontrar alguna vacuna con capacidad preventiva, así como en el desarrollo de tratamientos para frenar su expansión. No 
obstante, en todo momento los especialistas señalan a la prevención como la mejor arma para luchar contra esta enfermedad que lastra a tantas familias a nivel mundial.

Por lo que respecta a la transmisión de la enfermedad, se ha llevado a cabo de un modo gradual entre la población mediante contacto sexual y, de igual modo, por el intercambio accidental de sangre y transfusiones llevadas a cabo en centros de salud y hospitales. Si bien el virus puede estar en cualquier fluido corporal, los estudios han descrito que sólo está presente en cantidades importantes en la sangre, las secreciones vaginales y el semen, así como en la leche materna (Granados y López 2003, García et al. 2005).

En cuanto a complejidad de su estudio, la descripción de la enfermedad en la escuela se puede trabajar de manera progresiva desde los diferentes niveles educativos: el concepto básico y los mecanismos de lucha y transmisión de la enfermedad, dentro un marco generalista de enfermedades de transmisión sexual, se trabajan en tercer ciclo de Educación Primaria (dentro del programa de Educación para la Salud en la Escuela) y segundo ciclo de Educación Secundaria. Además, los orígenes y las causas de la misma se abordan en Bachillerato y Estudios Superiores.

Se define un modelo como una representación abstracta y simulada de un sistema o fenómeno que hace explícitos y visibles sus elementos centrales y que puede ser usado para generar explicaciones y predicciones (Schwartz et al. 2009). El uso de modelos es un elemento clave en la actividad científica (Giere 1999). Los modelos están producidos por la capacidad que tiene el ser humano de representar mentalmente la realidad, sirviendo para la construcción de explicaciones y la elaboración de predicciones. A través de su utilización se espera que los discentes comprendan los contenidos, ya sean fenómenos, hechos, conceptos anatómicos..., con el objetivo de poder predecir y actuar en el futuro (Martí 2012).

A continuación, se presenta una actividad en la que se muestra cómo la promiscuidad en el ser humano, desde el diseño de un modelo básico de reacción química, puede ser responsable de una rápida expansión de la enfermedad y la consiguiente lacra social derivada, si éste no es capaz de tomar las medidas adecuadas para la prevención efectiva (métodos de anticoncepción de barrera: preservativo masculino o femenino).

\section{Descripción de la actividad. Metodología}

La experiencia comienza en el laboratorio de Educación Secundaria donde los alumnos prepararon los reactivos que van a ilustrar el proceso de comprobación de la promiscuidad como mecanismo de expansión rápida de una enfermedad, basado en el modelo de elaboración de una sencilla reacción química (figura 1A). A cada alumno de la clase (constituida en este caso por 30 discentes de $4^{\circ}$ curso de Educación Secundaria Obligatoria y un único docente) se le dio un tubo de ensayo con idéntico volumen: 28 de ellos contenían 10 $\mathrm{ml}$ de alcohol etílico y los dos restantes contenían $10 \mathrm{ml}$ de una solución de fenolftaleína (indicador de $\mathrm{pH}$ ) al 0,5\%; esta disolución se elabora a partir de $0,1 \mathrm{~g}$ de fenolftaleína en 20 $\mathrm{ml}$ de etanol. Los tubos de ensayo se repartieron al azar entre los alumnos de la clase, no sabiendo éstos cuáles portaban la solución de indicador de $\mathrm{pH}$.

Con el objetivo de que los alumnos no provocaran el estruendo que podría llevarse a cabo con actividades de este tipo, la misma se llevó a cabo en el patio del centro (figura $2 \mathrm{~A}$ ). Una vez allí, los alumnos comenzaron la mezcla de los fluidos que portaban en sus tubos de ensayo, simulando de esta forma una conducta sexual promiscua. Para ello, un alumno dispensaba la mitad de su contenido en el tubo de ensayo de un compañero. Tras homogeneizar mediante la ayuda de un tapón de corcho, la misma operación la llevaba a cabo el segundo compañero sobre el tubo del primero. Al finalizar, debía quedar igual volumen en los tubos de ensayo. 
Para asegurarnos que la totalidad de la muestra analizada queda contaminada (objeto de llamada de atención entre el alumnado) es necesario que cada discente intercambie el material que porta su tubo de ensayo con la mitad de la clase. El tomar como número máximo de intercambios el que figura en esta experiencia radica en el tiempo de que se dispone para realizar la práctica en un centro de estudios, así como permitir una situación más cercana a la realidad, asegurándose el docente un $33 \%$ mínimo de posibles casos positivos en la muestra de trabajo. Por ello, esta operación se repitió, no más de cinco veces, con diferentes alumnos del grupo.
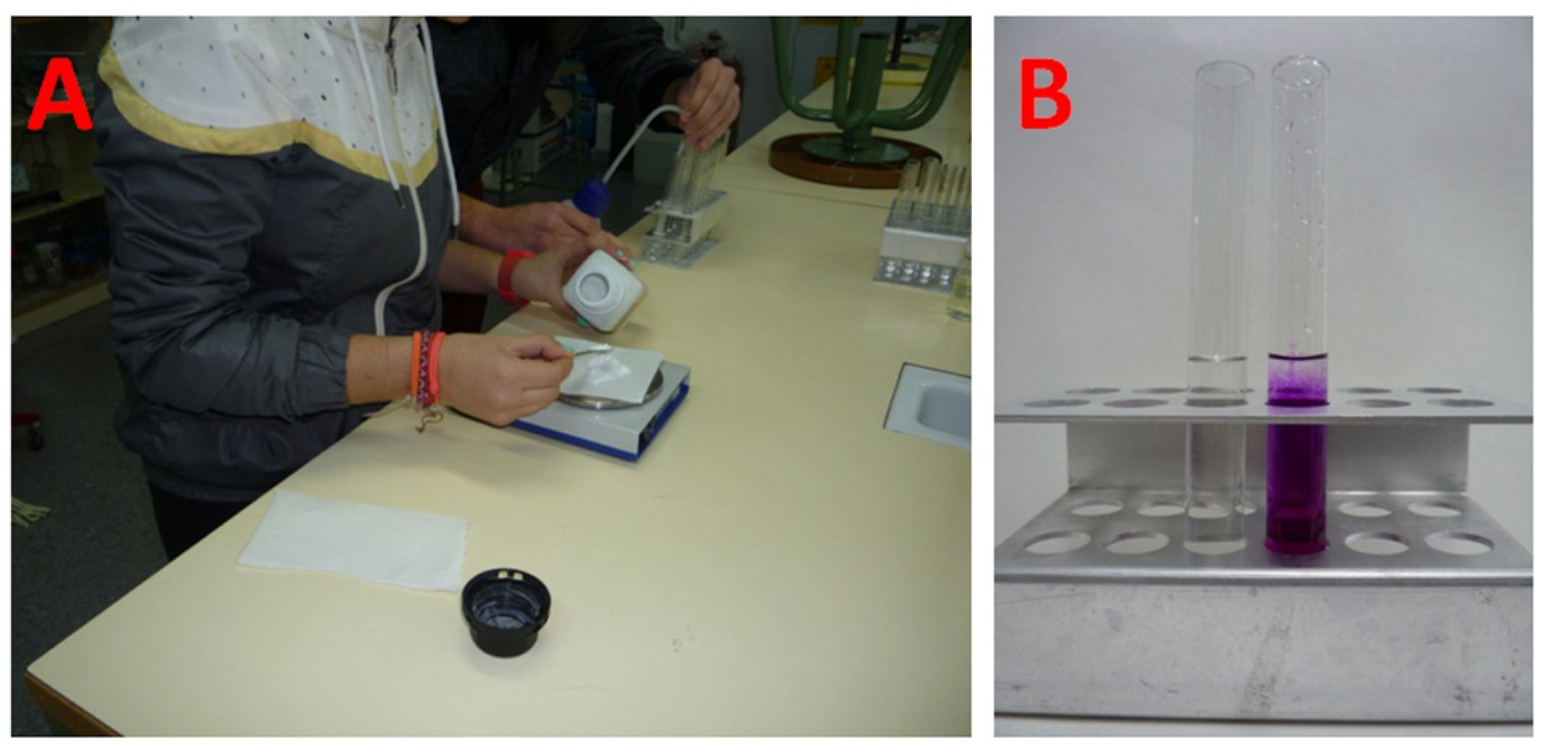

Figura 1. (A) Preparación de la fenolftaleína en solución alcohólica. (B) Revelado positivo (color morado) tras la adición de hipoclorito de sodio.

\section{Resultados y discusión}

Los tubos que portan la solución de fenolftaleína recrean los alumnos portadores de la infección por VIH. Estos tubos no se diferencian en nada respecto de aquellos que portan únicamente- el etanol. Esta metáfora científica, usada como herramienta didáctica para la comprensión del alumnado y no como nuevo concepto científico (Fernández-Rañada 1998, Cuadrado 2004), alude a la idea de presentar ante los alumnos quiénes creen ellos que pueden ser enfermos de SIDA o portadores del virus responsable de la enfermedad. En sus primeras etapas, la enfermedad cursa una evolución que no se aleja de la normalidad de una persona no infectada.

Tras el intercambio del material contenido en el tubo de ensayo entre el alumnado, que alude a un hipotético intercambio de fluidos, se procedió al revelado de cómo ha progresado la enfermedad en el grupo. Para ello, se vertieron unas gotas de hipoclorito de sodio (lejía) en cada tubo de ensayo (figura 2C). El cambio de color (de incoloro a rojo-morado) es indicativo de la presencia de indicador de $\mathrm{pH}$, aludiendo a un hipotético positivo (seropositivo) en la realidad (figura 1B). La figura 3 muestra la reacción química que tiene lugar entre el hipoclorito de sodio en agua y el cambio de color del indicador de $\mathrm{pH}$ mediante modificación interna de su estructura (López 2000).

Al finalizar la experiencia, sorprendió mucho entre los alumnos el elevado número de positivos que se presenta en la muestra ensayada (85-95\%). En este caso, el profesor debe hacer verdadero hincapié en el hecho de que el mantenimiento de relaciones sexuales azarosas, 
sin protección (métodos anticonceptivos de barrera), es el mecanismo más frecuente para sufrir el contagio del virus y el desarrollo posterior de la enfermedad.

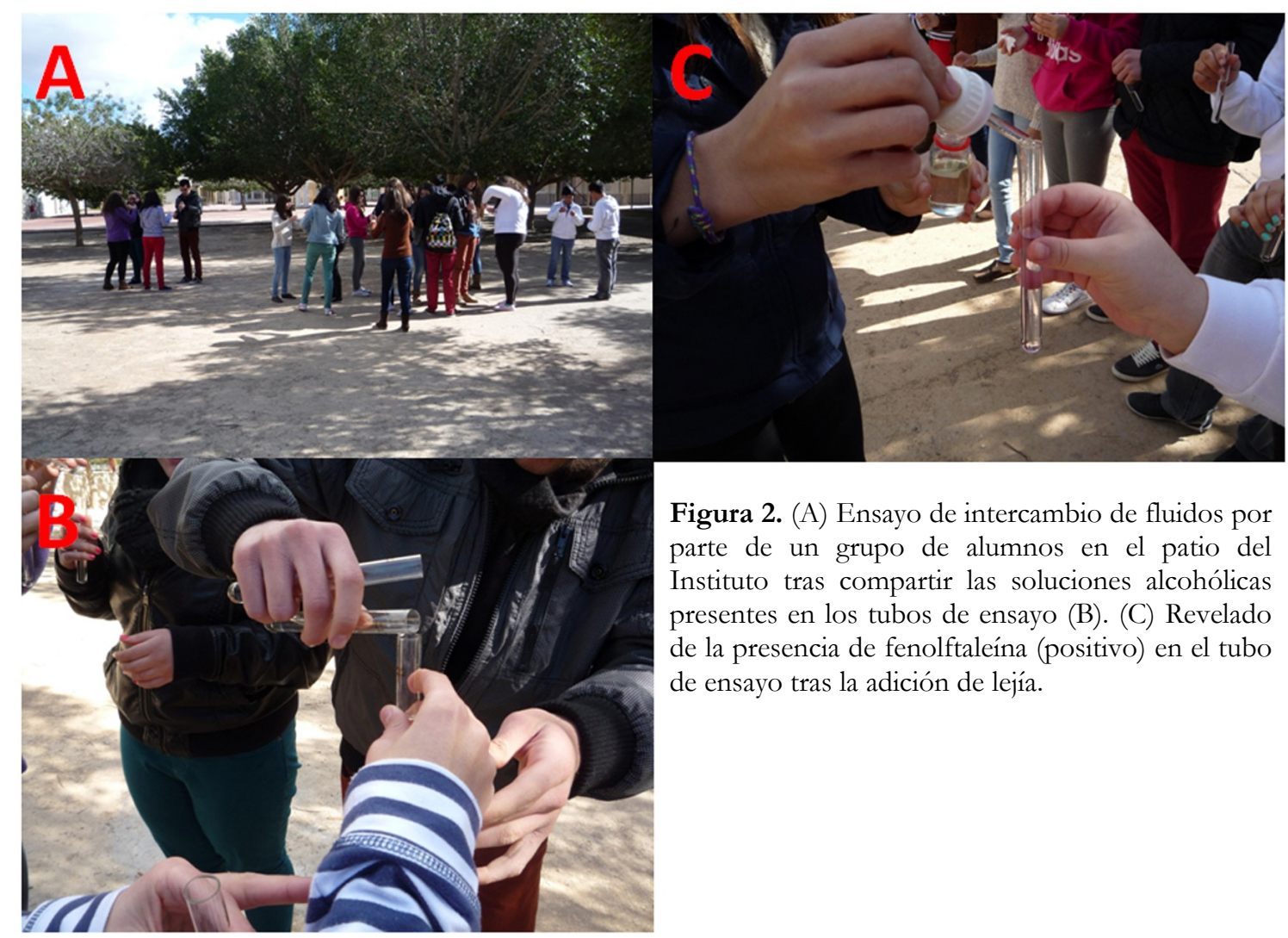

\section{¿Cómo se ha llevado a cabo esta experiencia?}

Con el objetivo final de poder afianzar en la medida de lo posible los contenidos teóricos que se abarcan en la materia de Biología y Geología para cuarto curso de Educación Secundaria Obligatoria, la visita al laboratorio y el empleo de materiales rutinarios pueden ser una herramienta muy útil para el docente, con el objetivo de que el alumnado pueda concebir la experiencia que se presenta como una ilustración empírica de los conocimientos teóricos aportados en el aula.

El conocimiento de las enfermedades de transmisión sexual, que se exponen de modo rápido a lo largo de los últimos cursos en la Educación Primaria y en tercer curso de ESO, como consecuencia de la densidad del temario a impartir por el docente, puede remediarse con el empleo de experiencias prácticas como la presentada en este trabajo.

La actividad práctica se preparó en dos sesiones. En una primera sesión, el docente marcó un breve recordatorio de aspectos teóricos de la enfermedad de SIDA, tal como (1) el agente responsable de la patología (VIH o virus de inmunodeficiencia humana), (2) los signos más evidentes de la enfermedad, basados en la caída del sistema inmunitario del ser humano enfermo, que conducen a una inadecuada respuesta contra posibles infecciones secundarias oportunistas, (3) los datos históricos de la enfermedad, detectada a principios de los años ochenta del siglo pasado, si bien el primer caso documentado se dató en 1959 en la República del Congo (Paño 2011), así como el análisis de la evolución de la enfermedad dentro de un contexto social como es el español, tal y como recoge en su informe de Miguel (1991) y (4), finalizando, con datos sobre la incidencia del SIDA en España, aportándose información 
sobre las tasas de nuevos enfermos diagnosticados y comprobándose la evolución negativa para nuestro país, si éste se compara con otros países del entorno europeo (VV.AA. 2012). Finalmente, después de toda la exposición, en una segunda sesión, el alumno fue quien trabajó en el laboratorio ilustrando empíricamente el mecanismo de transmisión del virus que desencadena la enfermedad de SIDA. La preparación de los reactivos que se iban a necesitar para la experiencia y su reparto en el patio del Instituto, se llevó a cabo por una pareja de alumnos. La actividad en el patio transcurrió en 20 minutos de la clase, repitiéndose con el objetivo de comprobar la sorpresa incipiente del alumnado, es decir, el alto índice de positividad en el grupo tras efectuar el intercambio de fluidos (etanol o etanol-fenolftaleína) cuando se procedió con el revelado. El alumnado quedó perplejo cuando, en un principio, todos eran iguales en cuanto a coloración del tubo de ensayo que portaban, no creyendo que con un hecho tan básico (intercambio con un desconocido) pudieran llegar a conseguir un resultado tan negativo entre el grupo. La transmisión y contagio del VIH es tal y como se recoge, de un modo metafórico, en esta experiencia. Es por ello que, el grado de acogida de este tipo de actividades prácticas entre el alumnado ha sido muy notable (lo que ha estado motivado, en gran parte, por los datos negativos expuestos sobre la enfermedad en la primera sesión). Además, y en palabras de los propios alumnos, correlacionar el modo de transmisión de un virus que ocasiona una enfermedad tan grave y marcada en nuestra sociedad con una experiencia de laboratorio de este tipo, da una información «muy clara y convincente» del modo de actuación del discente frente a esta enfermedad infecciosa y otras relacionadas que se transmiten de un individuo a otro por contacto sexual.

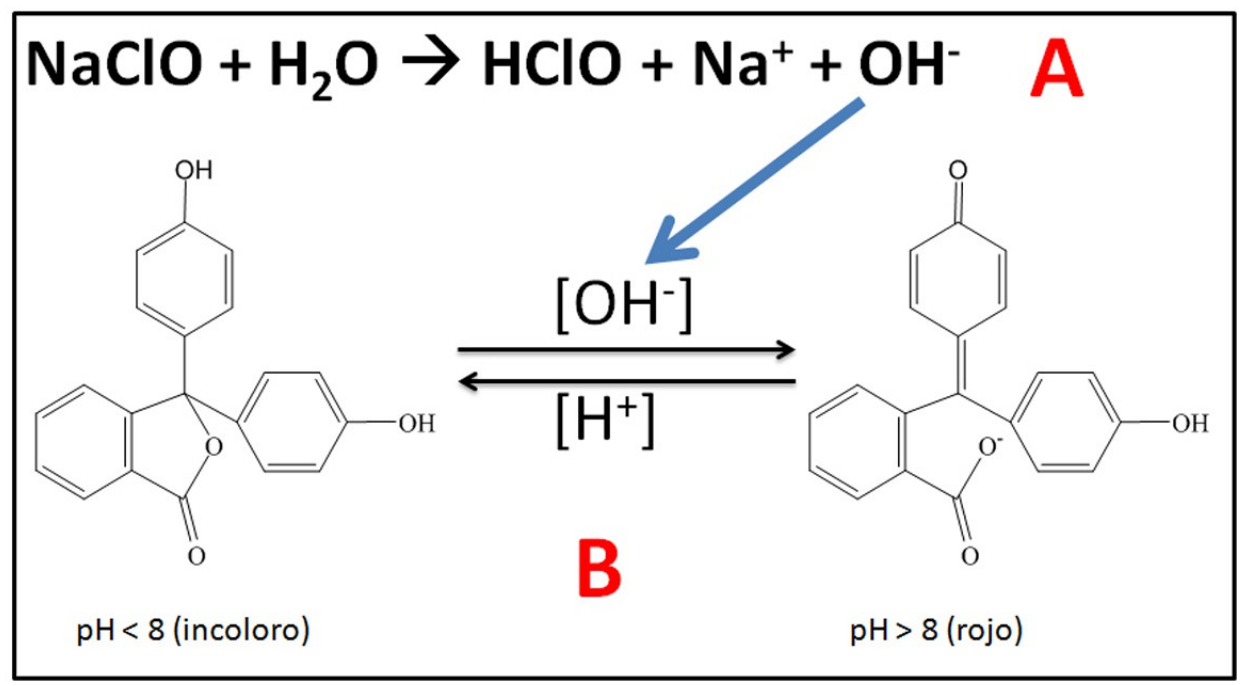

Figura 3. (A) Reacción de hidrólisis de la molécula de hipoclorito de sodio (lejía). (B) Estructura química del indicador de $\mathrm{pH}$ fenolftaleína en medio básico y ácido (López 2000).

La evaluación de la actividad práctica no se ha llevado a cabo con el rigor científico que debiera, siendo el único interés y preocupación del equipo de docentes que su alumnado conozca la ciencia en un Instituto de Educación Secundaria como algo más que conceptos e ideales teóricos, abriéndoles una nueva forma de comprensión y entendimiento de una materia.

\section{Materiales y aspectos a considerar}

Finalizada la experiencia, y como medida básica de higiene, es aconsejable el lavado de las manos con abundante agua y jabón. El material de trabajo de vidrio deberá dejarse unas horas en agua con hipoclorito de sodio, previo a su fregado escrupuloso. Los reactivos utilizados en 
la experiencia no se desecharán por el desagüe del grifo del laboratorio, vertiéndose en un frasco contenedor para su posterior recogida por personal autorizado.

\section{Agradecimientos}

Los autores quieren expresar su más sincero agradecimiento a todos los alumnos de $1^{\circ}, 3^{\circ}$ y 4 de Educación Secundaria del IES Ricardo Ortega de Fuente Álamo, Murcia (Curso 2012-2013), por el interesante trabajo realizado y las imágenes presentadas en esta actividad. De igual modo, están agradecidos a la catedrática jubilada de Educación Secundaria, D ${ }^{a}$ Juana Gil Bartolomé (IES de Candás, Asturias), por sus aportaciones matemáticas a este trabajo.

\section{Referencias bibliográficas}

BOE (2006) Real Decreto Real Decreto 1631/2006, de 29 de diciembre, por el que se establecen las enseñanzas mínimas correspondientes a la Educación Secundaria Obligatoria. $\mathrm{BOE} \mathrm{n}{ }^{\circ} 5,677-773$.

BOE (2007) Real Decreto 1467/2007, de 2 de noviembre, por el que se establece la estructura de bachillerato y se fijan sus enseñanzas mínimas. BOE nº 266, 45381-45477.

Cuadrado G. (2004) Metáfora, ciencia y Cultura: Propuesta de una nueva tipología para el análisis de la metáfora científica. Ibérica 7, 53-70.

de Miguel J. M. (1991) El problema social del SIDA en España. Reis 53, 75-105.

Fernández-Rañada A. (1998) De genes, cerebros y metáforas de la ciencia. Diario La Razón (12 de noviembre), Sección La Primera. p. 5.

García M., Furió J., García A., Sendra R., Varela X. (2005) Biología. $2^{\circ}$ Bacbillerato. Valencia. Editorial Ecir.

Giere R. (1999) Un nuevo marco para enseñar el razonamiento científico. Enseñanza de la Ciencias Número extra, 63-70.

Granados F., López V. (2003) $2^{\circ}$ B. Biología. Ciencias de la Naturaleza y de la Salud. Proyecto 2.2. Zaragoza. Editorial Edelvives.

López J. P. (2000) Microbiología de las aguas potables de redes de distribución urbana y caracterización de una bacteria típica de red. Tesis de licenciatura. Departamento de Genética y Microbiología. Universidad de Murcia. Inédito.

Martí J. (2012) Aprender a investigar, pp. 37-101 en Aprender ciencias en la Educación Primaria. Ciencias en Primaria 1. Barcelona. Editorial Graó.

OMS (2012) Diapositivas clase sobre epidemiologia. Organización Mundial de la Salud. ONUSIDA.

Paño A. (2011) El SIDA como enfermedad zoonótica. Journal of Feelsynapsis 2, 12-15.

Schwarz C. V., Reiser B. J., Davis E. A., Kenyon L., Achér A., Fortus D., Shwartz Y., Hug B., Krajcik J. (2009) Developing a learning progression for scientific modeling: making scientific modeling accessible and meaningful to learners. Journal of Research in Science Teaching 46(6), 632-654.

VV.AA. (2012) Vigilancia epidemiológica del VIH/SID A en España. Sistema de información sobre nuevos diagnosticados de VIH. Registro nacional de casos de SIDA. Sistemas automáticos de vigilancia epidemiológica. Centro Nacional de Epidemiología. Instituto Carlos III. Madrid. 